\title{
Potential impact of land use change on ecosystem services in China
}

\author{
Meng Wang • Xiaofang Sun
}

Received: 24 October 2015 / Accepted: 14 March 2016/Published online: 28 March 2016

(C) Springer International Publishing Switzerland 2016

\begin{abstract}
Land use change can greatly alter spatial pattern and overall ecosystem service values (ESV). The goal of this study was to explore the likely effects of land use change on ESV in China. In this paper, the spatially explicit land use changes across China from 2010 to 2020 under the 2000 s trend scenario and the planning scenario were projected using the Dyna-CLUE model. The ESV evaluation method was improved by adjusting the ESV coefficients using biomass data to reduce the generalization error of proxy-based method. The results revealed that between 2010 and 2020, total ESV increased by 1798 and 2215 billion $\mathrm{RMB} \mathrm{a}^{-1}$ under the 2000s trend scenario and the planning scenario, respectively. The spatial pattern of ESV in 2010 and 2020 presented a logical geographic distribution. The areas with ESV of 50,000 RMB ha ${ }^{-1} \mathrm{a}^{-1}$ and higher occurred primarily in northeastern and southern China, while the areas with ESV of $5000 \mathrm{RMB} \mathrm{ha}^{-1} \mathrm{a}^{-1}$ and lower were mainly located in northwestern China. The spatial differences between the two scenarios were insignificant except that the increase of ESV in southwestern China was more prominent in the planning scenario than that in the 2000s trend scenario, while the total
\end{abstract}

M. Wang $(\bowtie) \cdot X$. Sun

School of Geography and Tourism, Qufu Normal University, Rizhao 276800, China

e-mail: wmqfnu@126.com

X. Sun

Institute of Geographic Sciences and Natural Resources Research, Chinese Academy of Sciences, 11A, Datun Road, Chaoyang District, Beijing 100101, China
ESV in 2020 under the planning scenario was larger than that in the 2000s trend scenario. The increase of ESV occurred mainly in northeastern, southern, and southeastern China due to forest growth and woodland expansion in 2020 compared with 2010. The results of this study can provide useful information for the public and land managers to consider.

Keywords Spatial modeling - Ecosystem service values $\cdot$ Land use change $\cdot$ China

\section{Introduction}

Land use change is important to environmental management due to its influence on ecosystem services, climate change, and biodiversity (Foley et al. 2005; Newbold et al. 2015; Su et al. 2012). In fast-growing developing countries, such as China, the rapidly changing land use became increasingly dramatic. Therefore, sustainable trajectories of land use change are of great importance. Understanding the potential impacts of land use changes on ecosystem service values (ESV) may provide information for improving ecosystem services and functions of landscape (Wu et al. 2015). The effects of land use change on ecological environment and the value of ecosystem services have attracted the interest of many ecologists and geographers (Baral et al. 2014; Costanza et al. 2014; Fürst et al. 2013; Lawler et al. 2014; Li and Wu 2013; Song et al. 2015; Su et al. 2012).

In general, the methods to estimate ecosystem service values can be broadly divided into two groups: the first 
is primary data-based method, which is based on primary data from within the study region, and the other is proxy-based method (Eigenbrod et al. 2010). The proxy-based method has been widely used, which views land use type as a proxy of ecosystem services, and the variation of ecosystem service values is estimated by analyzing the changes in land use structure. Studies of this category have usually been carried out from the perspective of land use change and its effect on ecosystem services. Many researchers have investigated the ESVs of different ecosystems (TEEB 2010; Bateman et al. 2013). Costanza first classified the biosphere into 16 ecosystems and evaluated ESVs for 17 ecosystem service function types (Contanza et al. 1997). Costanza et al. (2014) revised the value according to their previous study and other related studies. Xie et al. (2008) evaluated the value coefficient of Chinese ecosystem by surveying 700 Chinese ecologists. The coefficients mentioned above have been widely used to assess ecosystem service values of different ecosystems. However, the proxy-based method is criticized for some reasons. The main problem is that it ignores spatial heterogeneity that may exert influence on the process of ecosystem changes, and the ESVs can be different within the same land use type due to variation of physical environment. Moreover, the ESV coefficients may change with time, which has not been considered in many studies. The primary data-based methods directly assess the ESVs using the primary data from within the study region. It can be subdivided further into maps based on representative sampling across the study region and into modeled surfaces based on primary data (Eigenbrod et al. 2010). The calculation process is relatively complicated, and some models have been developed, such as InVEST, MIMES, ARIES, SoLVES model, etc. The running of these models usually involves many input datasets and numerous parameters. Perhaps the greatest obstacle use the primary data-based method is insufficiency of data for most of the studies, especially for large scale studies, such as those at the national or global scale. Therefore, the primary data-based method is widely used in research at smaller areas or in research that identifies hotspots for ecosystem services (Andrew et al. 2014; Martínez-Harms and Balvanera 2012; Swetnam et al. 2011; Syswerda and Robertson 2014). It can be concluded that the advantage of primary databased method is high accuracy and the disadvantage the complexity, while the proxy-based method (value transfer method) is relatively easier to operate but the accuracy is usually a challenge. In addition, in some cases, land use changes may increase some ecosystem services but at the expense of others (Lawler et al. 2014). For example, the increase in woodland could lead to increase in timber production and species conservation, but decrease in food production. Such tradeoff can make it difficult to provide policy advice. Pricing the ecosystem services would allow the comparison of value changes of each ecosystem service in a common monetary metric.

Few studies are available to investigate ESV variations from land use change across China. Particularly, analysis of spatial difference of ESV changes due to land use change across the whole China is still lacking (Wang et al. 2014). Wang et al. (2014) examined the impact of land use change from the 1980s to 2010 on the ESVs, compared the spatial differences, and optimized land use structure to maximize the total ESVs in 2020. Their results were very useful for land managers. Unfortunately, they failed to estimate the spatial pattern of land use change and ESVs in the future, which may provide useful information for land use planning and the enhancement of ESVs. The CLUE model, a dynamic model to simulate the spatial pattern of land use change, has been successfully used across countries and even continents (Jiang et al. 2015; Verburg and Overmars 2009; Zheng et al. 2015). It helps explore future land use patterns. Finally, the spatial heterogeneity of ESV changes can be examined based on the simulated land use pattern and ecosystem valuation approach. In this study, we attempt to explore potential impacts of land use change on ESVs. Specifically, the purposes of our study are to (1) predict spatially explicit land use changes across China using Dyna-CLUE model, (2) develop an improved method for estimating ESVs based on value transfer method, and (3) simulate how ESVs change under different land use scenarios.

\section{Study area and data sources}

\section{Study area}

The territory of China is situated approximately between $18^{\circ} \mathrm{N}$ and $54^{\circ} \mathrm{N}$, and $73^{\circ} \mathrm{E}$ and $135^{\circ} \mathrm{E}$, covering 34 provinces and encompassing an area of approximately $9,600,000 \mathrm{~km}^{2}$. The plateau and mountainous regions account for about $60 \%$ of the total land area, while plains account for one fifth, and the rest consists of 
basins and hills. The climate is dominated by a continental monsoon climate. Seasonal changes and annual variability of temperature and precipitation are significant in most regions of China, which are major factors in the formation of complex and diverse climate as well as topography (Chi et al. 2015).

\section{Data sources}

Our study includes land use data, forest inventory data, climatic and demographic data, socioeconomic data, natural reserve distribution data, development policy data, and ecosystem services value coefficients.

Land use maps of China for 2000, 2005, and 2010 were provided by the Institute of Remote Sensing and Digital Earth, Chinese Academy of Sciences (Liu et al. 2003). Land use data types were classified into six categories: cropland, grassland, woodland, water area, built-up land, and unused land (Table 1). The grid size of land use data was resampled to $2 \times 2 \mathrm{~km}\left(4 \mathrm{~km}^{2}\right)$ in this study.

Land use development policy data were provided by the Chinese government (National General Land Use Planning Outline 2008). The market price of agricultural production was obtained from China's statistical yearbook, the food production data from cropland for each province from China's agricultural statistics yearbook, and the forest age data around 2010 from the China's national forest inventory database during 2009-2013. The province-specific biomass densities for woodland, cropland, grassland were obtained from published literature (Fang et al. 1996, 1998; Piao et al. 2007, 2009). The physical and socioeconomic datasets used as

Table 1 Description of land use types

\begin{tabular}{ll}
$\begin{array}{l}\text { Type of land } \\
\text { use }\end{array}$ & Descriptions \\
\hline Cropland & $\begin{array}{l}\text { Irrigated and non-irrigated cropland } \\
\text { Natural and man-made grassland with a ground- } \\
\text { coverage higher than } 5 \%\end{array}$ \\
Woodland & $\begin{array}{l}\text { Woodland arbor, shrubbery, bamboo, and orchard } \\
\text { River, lake, reservoirs, water facilities, shallows, } \\
\text { and wetland. }\end{array}$ \\
Water area & $\begin{array}{r}\text { Land for cities and town, industrial, transportation, } \\
\text { and residential quarters in rural areas }\end{array}$ \\
Built-up land & $\begin{array}{r}\text { Desert, gobi, bare ground, bare rock, sandy land, } \\
\text { and other unused lands }\end{array}$ \\
Unused land &
\end{tabular}

driving factors for land use location, including elevation, slope, soil texture, temperature, precipitation, traffic, population, gross regional domestic product, and so on have been collected in one of our previous studies (Sun et al. 2015), and here, the datasets were directly used. The natural reserve data were collected by our previous study (Fan et al. 2013).

\section{Methodology}

Spatially explicit land use change modeling

The changes in national land use claims mentioned above are spatially allocated using the Dyna-CLUE model based on dynamic simulation of competition between land uses (Verburg and Overmars 2009). Spatial allocation rules can be specified based on empirical analysis, user-specified decision rules, and neighborhood characteristics. A detailed description of the Dyna-CLUE model is given by Verburg and Overmars (2009). The actual allocation accounts for constraints defined by the model user based on the processes and constraints relevant to the scenarios and characteristics of land use types (Verburg and Overmars 2009). The settings and data inputs can be classified into four categories: (1) land use requirements, (2) location suitability, (3) conversion rules, and (4) spatial policies and restrictions.

\section{Land use requirement}

Two scenarios of land use change at the national level from 2010 to 2020 are developed in this study: the 2000 s trend scenario is developed based on the extrapolation of land use trends from 2000 to 2010; and the planning scenario is projected using land use-related policy objectives. In the planning scenario, spatial patterns of land use change are simulated based on the national development targets of each land use type adopted by the sector administration of the Chinese Government (National General Land Use Planning Outline 2008). Land use requirements for each land use type under the two scenarios are shown in Table 2.

\section{Location suitability}

Location suitability is a major determinant of the competitive advantage of different land use types at a 
Table 2 Total area of each land use type in 2020 in the two scenarios $\left(\times 10^{4} \mathrm{~km}^{2}\right)$

\begin{tabular}{lllllll}
\hline & Cropland & Woodland & Grassland & Water area & Built-up land & Unused land \\
\hline 2000s trend scenario & 181.68 & 240.91 & 265.40 & 18.75 & 15.65 & 228.19 \\
Planning scenario & 182.36 & 250.22 & 280.56 & 21.06 & 12.22 & 204.14 \\
\hline
\end{tabular}

specific location (Verburg and Overmars 2009). Logistic stepwise regression was used to quantify location preferences of different land use types based on the relation between the occurrence of a land use type and physical and socioeconomic conditions (driving factors) of the location. The logistic regression uses land use type as dependent variable and land use driving factors as independent variable. In this study, the driving factors include demographic, soil-related, traffic, geomorphologic, and climatic variables. The factors are selected based on expert experience and literature review. Two categories of driving factors are distinguished in this study. The first type of driving factors are supposed to remain constant from 2005 to 2020 (e.g., altitude, slope, and soil texture), while the second type of changes (e.g., main road distribution, railway distribution, and population) will change in the future, namely dynamic driving factors. The traffic data sets in 2010 and 2020 were taken from the mid- and long-term engineering system planning map of China. The population data sets in the future were derived with the surface modeling of population distribution method (Yue et al. 2005a, b).

\section{Land use type specific conversion rules}

Since land use types have distinctive features that cause differences in conversion behavior, each land use type is characterized with a set of conversion rules and conversion elasticity indices. In this study, the parameterization of the conversion rules and conversion elasticity for each land use types are calibrated based upon a combination of experts' judgment and knowledge of specific conversion processes. Built-up land is allowed to be converted to cultivated land, and cultivated land to built-up land, grassland, and forest. The conversion from built-up land to forest and grassland is not allowed. The grassland is allowed to be converted to built-up land and cultivated land outside the natural reserve. The forest outside the natural reserve is allowed to be converted to built-up land, cultivated land, and grassland. The conversion elasticity implies the reversibility of land use change, which ensures the influence of current land use pattern on the future pattern (McConnell et al. 2004). The value of the conversion elasticity ranges from 0 (easy conversion) to 1 (irreversible change). In this study, the conversion elasticity values for built-up land, cultivated land, grassland, forest, water area, and others are set to be $1,0.7,0.6,0.9,1$, and 0.3 , respectively.

\section{Spatial policies and restrictions}

Spatial policies restrict certain land use change in designated areas. In this study, the conversion from grassland, shrub, and forest to built-up and cultivated land is not allowed within the natural reserve areas, suggesting that people cannot disturb the ecosystem in nature preservation zones.

After setting the parameters of the Dyna-CLUE model, the probability for each grid cell was calculated based on location suitability, conversion rules, and conversion elasticity. An iterative procedure was performed until total allocated area of each land use type equaled total land demands specified in the scenarios. Validation of the Dyna-CLUE model was performed. Setting 2000 as the initial year, with historical areas of 2000, 2005, and 2010 for each land use type, the land use pattern of 2010 was simulated by the Dyna-CLUE using the parameters mentioned above. Simulated land use distribution for 2010 was compared with the observed data for 2010 to evaluate the allocation algorithm and the relationships between land use types and driving factors. Kappa coefficient is frequently used for evaluating the prediction performance of the classifiers. However, the kappa coefficient was criticized by some authors recently. It was reported that kappa indices failed to provide useful information because they attempt to compare accuracy to a baseline of randomness, and some kappa indices have fundamental conceptual flaws (Pontius and Millones 2011). Two measures of quantity disagreement and allocation disagreement prove to be useful to summarize a cross-tabulation matrix than the kappa indices. Therefore, in our study, the 
evaluation of spatial agreement between simulated and observed land use data was based on the two new proportions: the quantity disagreement and allocation disagreement (Pontius and Millones 2011).

Assessment of ecosystem service

\section{Assignment of the ESV coefficient}

Xie et al. (2008) proposed a method to value the ecosystem services in China by surveying more than 700 Chinese ecologists. This method has been widely adopted to calculate ecosystem services in China, which classifies ecosystem services into four categories: supplying services consist of food production and raw material supply; regulating services consist of gas regulation, climate regulation, hydrological regulation, and waste treatment; supporting services consist of soil formation and retention and biodiversity protection; and cultural services consist of recreation and culture (Xie et al. 2008). The method set the function of food production as standard, with its equivalent ESV coefficient as 1 , and coefficients of other functions were equivalent values compared with the standard value of 1 (Table 3).

The ESVs calculated by Xie et al. (2008) are based on the grain price in 2007. Since the price index has increased rapidly in recent years in China, the ESV per unit was recalculated in this study based on the grain price in 2010 using the method proposed by Wang et al. (2014). The average natural food production data from cropland per hectare per year and the market price of foodstuffs from 2010 were used to calculate local ESVs (Wang et al. 2014). The average price for foodstuff was about $2.02 \mathrm{RMB} \mathrm{kg}^{-1}$, and the average annual food production from cropland between 1985 and 2010 were calculated for each regions based on the provincial data. Calculated ESVs for each land use type in different regions of China were shown in Table 4.

\section{Adjustment of the ecosystem services values}

The ecosystem service value coefficients in Table 3 were the mean values for each land use type. It is well known that the ESV has a good positive correlation with biomass. The biomass varies greatly spatially for the woodland. Therefore, to cope with the effect of heterogeneity on ESV valuation, biomass data were used to adjust ecosystem service values for the woodland.

$P_{\text {adjusted }}=\frac{b}{B} \times P_{0}$

where $P_{\text {adjusted }}$ is the adjusted ESV per unit for each grid cell within the wood land, $P_{0}$ is the ESV before adjustment, $b$ represents the biomass of the grid cell, and $B$ is the average biomass per unit of woodland.

The distribution of biomass from 2010 to 2020 in China was calculated using the density method based on the future land use patterns and province-specific biomass densities (Sun et al. 2015). It is assumed that biomass densities of grassland and cropland within a province are constant. The biomass density of woodland varies with age. Therefore, woodland biomass densities were modified by age based on their empirical relations (Nabuurs et al. 2007). The age of woodland in 2010 was obtained from the national forest inventory during

Table 3 Equivalent value coefficients of ecosystem services in China proposed by Xie et al. which were developed by surveying 700 Chinese ecologists

\begin{tabular}{|c|c|c|c|c|c|c|}
\hline First level & Second level & Cropland & Woodland & Grassland & Water & Unused \\
\hline \multirow[t]{2}{*}{ Supplying services } & Food production & 1 & 0.33 & 0.43 & 0.45 & 0.02 \\
\hline & Raw material & 0.39 & 2.98 & 0.36 & 0.30 & 0.04 \\
\hline \multirow[t]{4}{*}{ Regulating services } & Gas regulation & 0.72 & 4.32 & 1.5 & 1.46 & 0.06 \\
\hline & Climate regulation & 0.97 & 4.07 & 1.56 & 7.81 & 0.13 \\
\hline & Hydrological regulation & 0.77 & 4.09 & 1.52 & 16.11 & 0.07 \\
\hline & Waste treatment & 1.39 & 1.72 & 1.32 & 14.63 & 0.26 \\
\hline \multirow[t]{2}{*}{ Supporting services } & Soil formation and retention & 1.47 & 4.02 & 2.24 & 1.20 & 0.17 \\
\hline & Biodiversity protection & 1.02 & 4.51 & 1.87 & 3.56 & 0.4 \\
\hline Cultural services & Recreation and culture & 0.17 & 2.08 & 0.87 & 4.57 & 0.24 \\
\hline
\end{tabular}

From Xie et al. (2008) 
Table 4 ESVs for each land use type in different regions of China $\left(\mathrm{RMB} \mathrm{ha}^{-1} \mathrm{a}^{-1}\right)$

\begin{tabular}{|c|c|c|c|c|c|c|}
\hline & & Cropland & Woodland & Grassland & Water & Unused \\
\hline \multirow[t]{5}{*}{ North } & Supply & 1395.5864 & 3323.3024 & 793.17489 & 752.56324 & 60.24129 \\
\hline & Regulating & 3865.4731 & 14257.068 & 5923.7112 & 40146.74 & 522.0912 \\
\hline & Supporting & 2500.0073 & 8564.2808 & 4126.5175 & 4776.268 & 572.2923 \\
\hline & Cultural & 170.68323 & 2088.3592 & 873.4964 & 4585.6187 & 240.9652 \\
\hline & Total & 7931.75 & $28,233.01$ & $11,716.90$ & $50,261.19$ & 1395.59 \\
\hline \multirow[t]{5}{*}{ Northeast } & Supply & 1773.1579 & 4222.4123 & 1007.7658 & 956.1669 & 76.53928 \\
\hline & Regulating & 4911.2647 & 18114.276 & 7526.3524 & 51008.317 & 663.3404 \\
\hline & Supporting & 3176.3764 & 10881.322 & 5242.9337 & 6068.4726 & 727.1232 \\
\hline & Cultural & 216.86104 & 2653.3588 & 1109.8181 & 5826.2436 & 306.1571 \\
\hline & Total & $10,077.66$ & $35,871.37$ & $14,886.87$ & $63,859.20$ & 1773.16 \\
\hline \multirow[t]{5}{*}{ East } & Supply & 1958.0684 & 4662.7389 & 1112.8589 & 1055.879 & 84.52101 \\
\hline & Regulating & 5423.4268 & 20003.291 & 8311.2243 & 56327.626 & 732.5154 \\
\hline & Supporting & 3507.6189 & 12016.061 & 5789.6834 & 6701.3122 & 802.9496 \\
\hline & Cultural & 239.47599 & 2930.0595 & 1225.5534 & 6433.8228 & 338.084 \\
\hline & Total & $11,128.59$ & $39,612.15$ & $16,439.32$ & $70,518.64$ & 1958.07 \\
\hline \multirow[t]{5}{*}{ Mid-south } & Supply & 1848.012 & 4400.6615 & 1050.3087 & 996.53154 & 79.77022 \\
\hline & Regulating & 5118.5945 & 18878.971 & 7844.0778 & 53161.636 & 691.3419 \\
\hline & Supporting & 3310.4676 & 11340.677 & 5464.2644 & 6324.6535 & 757.8171 \\
\hline & Cultural & 226.01586 & 2765.3704 & 1156.6691 & 6072.1989 & 319.0809 \\
\hline & Total & $10,503.09$ & $37,385.68$ & $15,515.32$ & $66,555.02$ & 1848.01 \\
\hline \multirow[t]{5}{*}{ Southwest } & Supply & 1720.0564 & 4095.9626 & 977.58608 & 927.53244 & 74.24719 \\
\hline & Regulating & 4764.1849 & 17571.803 & 7300.9593 & 49480.764 & 643.4757 \\
\hline & Supporting & 3081.2521 & 10555.456 & 5085.9225 & 5886.7392 & 705.3483 \\
\hline & Cultural & 210.36661 & 2573.8979 & 1076.5821 & 5651.7643 & 296.9888 \\
\hline & Total & 9775.86 & $34,797.12$ & $14,441.05$ & $61,946.80$ & 1720.06 \\
\hline \multirow[t]{5}{*}{ Northwest } & Supply & 1677.8268 & 3995.4007 & 953.58551 & 904.76023 & 72.42432 \\
\hline & Regulating & 4647.218 & 17140.39 & 7121.7146 & 48265.942 & 627.6774 \\
\hline & Supporting & 3005.6034 & 10296.305 & 4961.0588 & 5742.2116 & 688.031 \\
\hline & Cultural & 205.20184 & 2510.705 & 1050.1511 & 5513.0057 & 289.6973 \\
\hline & Total & 9535.85 & $33,942.80$ & $14,086.51$ & $60,425.92$ & 1677.83 \\
\hline
\end{tabular}

2009-2013, while in the future, they were obtained from the output of Dyna-CLUE model that tracked the year of woodland establishment and clearing.

\section{Results}

Change in the spatial structure of land use in China from 2010 to 2020

The simulated and observed land use data of 2010 were compared to validate the performance of the land use model using two parameters: quantity disagreement and allocation disagreement. The quantity disagreement is 0.02 and the allocation disagreement is 0.16 , indicating that the Dyna-CLUE model and the parameters can specify the location quiet well.

The spatial distributions of six land use types were explained well by selected physical and socioeconomic location factors as indicated by the ROC (receiver operating characteristic) values that indicate the goodnessof-fit of the logistic regression models. High ROC values were found for built-up land (0.976), cropland (0.916), and water area (0.913).

Spatial patterns of land use in 2010 and changes between 2010 and 2020 under the 2000s trend scenario 
and planning scenario are shown in Fig. 1. The model projects substantial land use change between 2010 and
2020 under both the 2000s trend scenario and the planning scenario. The cropland is projected to shrink under

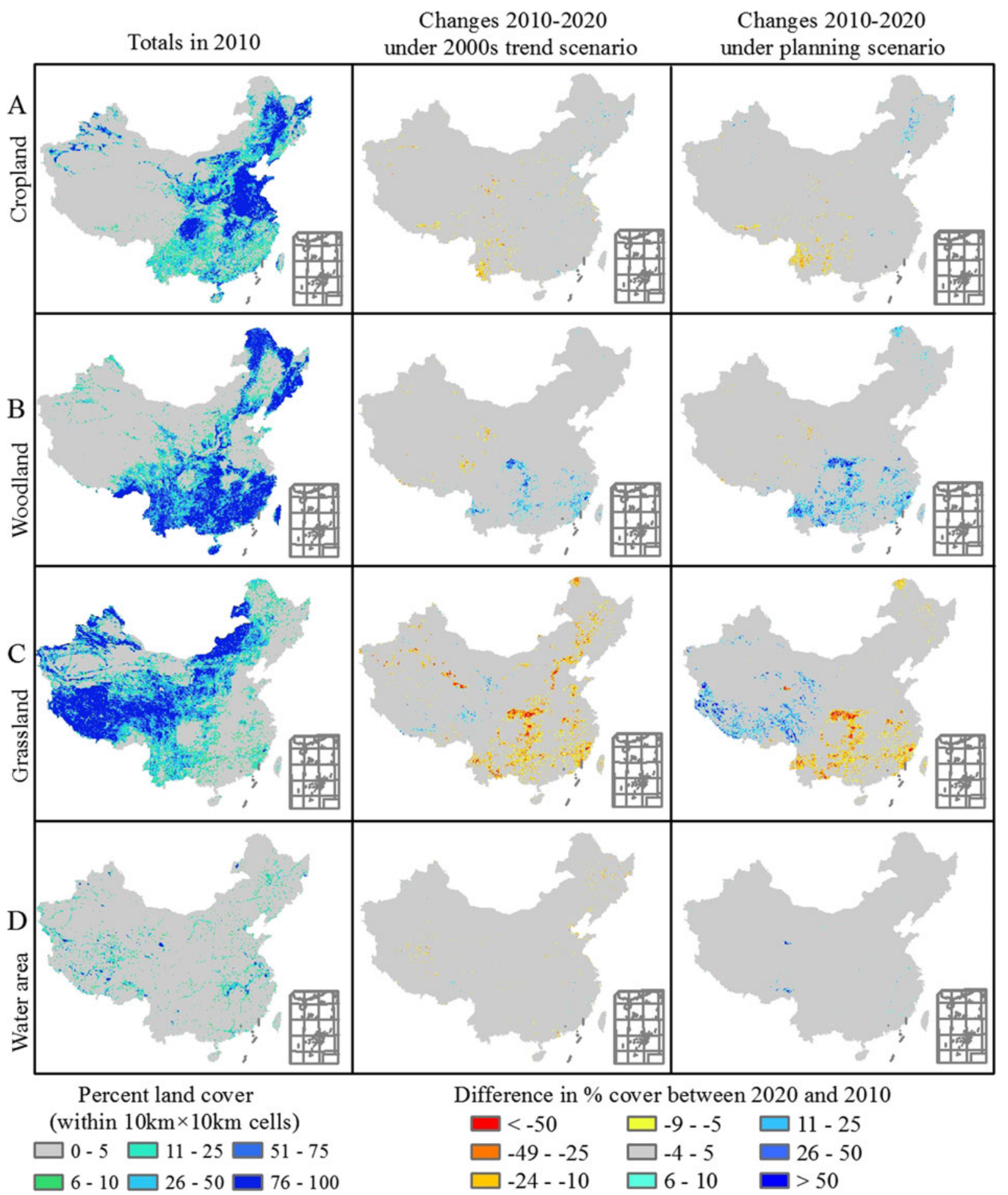

Fig. 1 Spatial patterns in land use in 2010 and changes between 2010 and 2020 under the 2000 s trend scenario and the planning scenario, for cropland (a), woodland (b), grassland (c), and water area (d) 
both scenarios. The total decreased areas of cropland are 19,956 and $13,135 \mathrm{~km}^{2}$ for the 2000s trend scenario and the planning scenario, respectively. The loss in cropland is primarily in southwestern and eastern China where urban growth is rapid. In recent years, the government has been taking measures to slow down the loss of cropland to ensure food security. Therefore, some locations would be converted to cropland to make up lost areas due to urban growth. In northeastern China, which is an important agricultural region in China, some abandoned cropland would be recovered in 2020 (Fig. 1a). The woodland area showed modest increase under the 2000 s trend scenario and large increase under the planning scenario, with the increase of 42,708 and $135,842 \mathrm{~km}^{2}$ under the 2000s trend scenario and the planning scenario, respectively. The forest coverage would be $26.5 \%$ under the planning scenario. The increase of woodland is primarily in the southern China under both scenarios (Fig. 1b). We project a large decrease in grassland, with a decrease of $6 \%$ under the 2000 s trend scenario. The decrease of grassland would happen primarily in the fringe of grassland (Fig. 1c). While in the planning scenario, the government will take measures to contain fast deterioration of grassland, and the grassland would have a complex pattern of gains and losses. Water area has been obviously diminished in the past decades, and the trend is also obvious under the 2000 s trend scenario. Water area protection has attracted the attention of the government. The decline would be slowed down or stopped under the planning scenario. The artificial wetland construction or returning cropland to lake measures would take place in some locations (Fig. 1d).

\section{Ecosystem service value change analysis}

Based on simulated land use data, the ESVs for each land use category in different regions of China (Table 3), and the biomass data to adjust the ESV coefficients, the ESV map for the future can be produced. First, biomass distribution data were calculated using the biomass density approach taking forest age into consideration. Figure 2 shows the spatial pattern of biomass in 2010 and 2020 under the two scenarios. We can see that the spatial variability in biomass is considerable, so the adjustment of the ESV coefficients based on the biomass data is necessary to better understand the spatial pattern of ESV in China.
Table 5 is a summary of the ESV valuation results. We estimated that ecosystems provide RMB $18,766.94,20,565.52$, and 20,981.82 billion worth of services annually for 2010, 2020 under the 2000s trend scenario, and 2020 under the planning scenario, respectively. Approximately $60 \%$ of the total ESV was contributed by woodland. The grassland, cropland, and water area contributed approximately 18,8 , and $5 \%$, respectively. With the increase in woodland, forest growth, and other land use conversions, the increases in overall ESV of the 2000s trend scenario and the planning scenario were 1798 and 2215 billion Yuan $\mathrm{RMB} \mathrm{a}^{-1}$, respectively. Take the planning scenario as an example; the overall ESV increased by $11.8 \%$, the supplying service value by $13.1 \%$, the regulating service value by $11.6 \%$, the supporting service value by $11.6 \%$, and the cultural service value by $12.1 \%$. The ESV values of cropland and grassland in 2020 decreased under both scenarios compared with that in 2010. The ESV value of woodland increased under both scenarios, and the increment is higher under the planning scenario than the 2000s scenario. The ESV value of water area in 2020 increased compared with that in 2010 under the planning scenario while decreased under the 2000s scenario (Table 5).

The ESV maps in 2010 and the spatial distribution of ESV changes from 2010 to 2020 under the two scenarios were created based on land use data and ESV coefficients (Fig. 3). These maps reveal more spatially detailed information. The biomass data was applied to produce a more reasonable spatial distribution of ESVs. We found that the ESV map represents a logical geographic distribution. Water area and woodland with high biomass, such as those in northeastern and southwestern China show high ESVs. The lowest ESVs occur primarily in northwestern China, where the land use types are mainly desert, sandy land, and gobi. The southwestern and eastern China covered by grassland and cropland have moderate ESVs. The spatial differences between the two scenarios are insignificant, while the increase of ESV in southwestern China is more prominent under the planning scenario than the 2000s trend scenario (Fig. 3b, c). The results of the scenario analysis show that land use changes may lead to a continuous increase in the ESV especially in southern China during the years 2010-2020 (Fig. 3d, e).

Temporal changes of various ecosystem services, namely the supplying service, the regulating service, the supporting service, and the cultural service across 


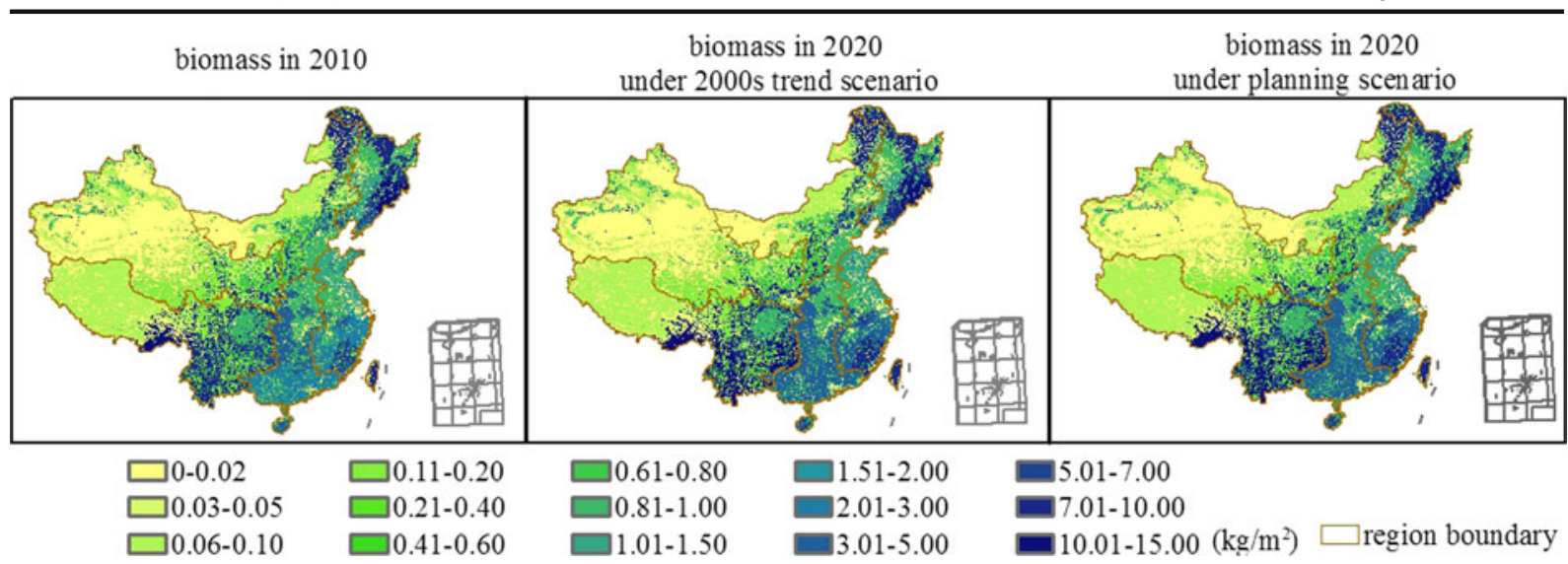

Fig. 2 Spatial pattern of biomass in China in 2010, 2020 under 2000s trend scenario, and 2020 under planning scenario

the period 2010-2020 under the 2000s trend scenario and the planning scenario for different regions, was evaluated using the ESV of 2010 as the baseline (Fig. 4). We found that the increase of the ecosystem services value increased largest in mid-south region compared with other regions. One reason is that the expansion of woodland and decrease in grassland were the main changes in the mid-south region. The increases in the east region and southwest region are also significant. The reason is that in the east, southwest, and mid- south region, woodland is the main land use type (Fig. 1), and the forest age in these regions are young (Sun et al. 2015); thus, the increase of forest biomass is fast, which results in the increase of ESV values.

\section{Discussion}

We synergistically combined land use data, biomass distribution data, and ESV coefficients to generate

Table 5 ESV values in 2010 and 2020 under the two scenarios for different land use types (billion RMB a ${ }^{-1}$ )

\begin{tabular}{|c|c|c|c|c|c|c|}
\hline Region & Scenario & Supplying services & Regulating services & Supporting services & Cultural services & Total ESV \\
\hline \multirow[t]{3}{*}{ Cropland } & 2010 & 319.84 & 885.95 & 572.96 & 39.04 & 1817.79 \\
\hline & $2020(2000$ s trend $)$ & 316.43 & 876.51 & 566.86 & 38.63 & 1798.43 \\
\hline & 2020 (planning) & 317.71 & 880.05 & 569.15 & 38.78 & 1805.69 \\
\hline \multirow[t]{3}{*}{ Woodland } & 2010 & 1345.05 & 5771.02 & 3466.66 & 845.18 & 11427.90 \\
\hline & $2020(2000$ s trend $)$ & 1595.87 & 6847.22 & 4113.13 & 1002.80 & 13559.03 \\
\hline & 2020 (planning) & 1607.30 & 6896.25 & 4142.58 & 1009.98 & 13656.12 \\
\hline \multirow[t]{3}{*}{ Grassland } & 2010 & 264.05 & 1972.90 & 1374.35 & 290.84 & 3902.14 \\
\hline & $2020(2000$ s trend $)$ & 247.37 & 1848.27 & 1287.53 & 272.46 & 3655.64 \\
\hline & 2020 (planning) & 261.83 & 1956.29 & 1362.78 & 288.39 & 3869.28 \\
\hline \multirow[t]{3}{*}{ Water area } & 2010 & 19.06 & 1017.32 & 121.02 & 116.19 & 1273.60 \\
\hline & $2020(2000$ s trend $)$ & 17.77 & 948.54 & 112.84 & 108.34 & 1187.49 \\
\hline & 2020 (planning) & 19.85 & 1059.53 & 126.04 & 121.01 & 1326.44 \\
\hline \multirow[t]{3}{*}{ Unused land } & 2010 & 14.85 & 129.28 & 141.82 & 59.56 & 345.51 \\
\hline & $2020(2000$ s trend $)$ & 15.68 & 136.55 & 149.79 & 62.91 & 364.94 \\
\hline & 2020 (planning) & 13.94 & 121.34 & 133.11 & 55.90 & 324.29 \\
\hline \multirow[t]{3}{*}{ Total } & 2010 & 1962.85 & 9776.47 & 5676.81 & 1350.82 & 18766.94 \\
\hline & $2020(2000$ s trend $)$ & 2193.14 & 10657.09 & 6230.15 & 1485.15 & 20565.52 \\
\hline & 2020 (planning) & 2220.63 & 10913.46 & 6333.66 & 1514.07 & 20981.82 \\
\hline
\end{tabular}




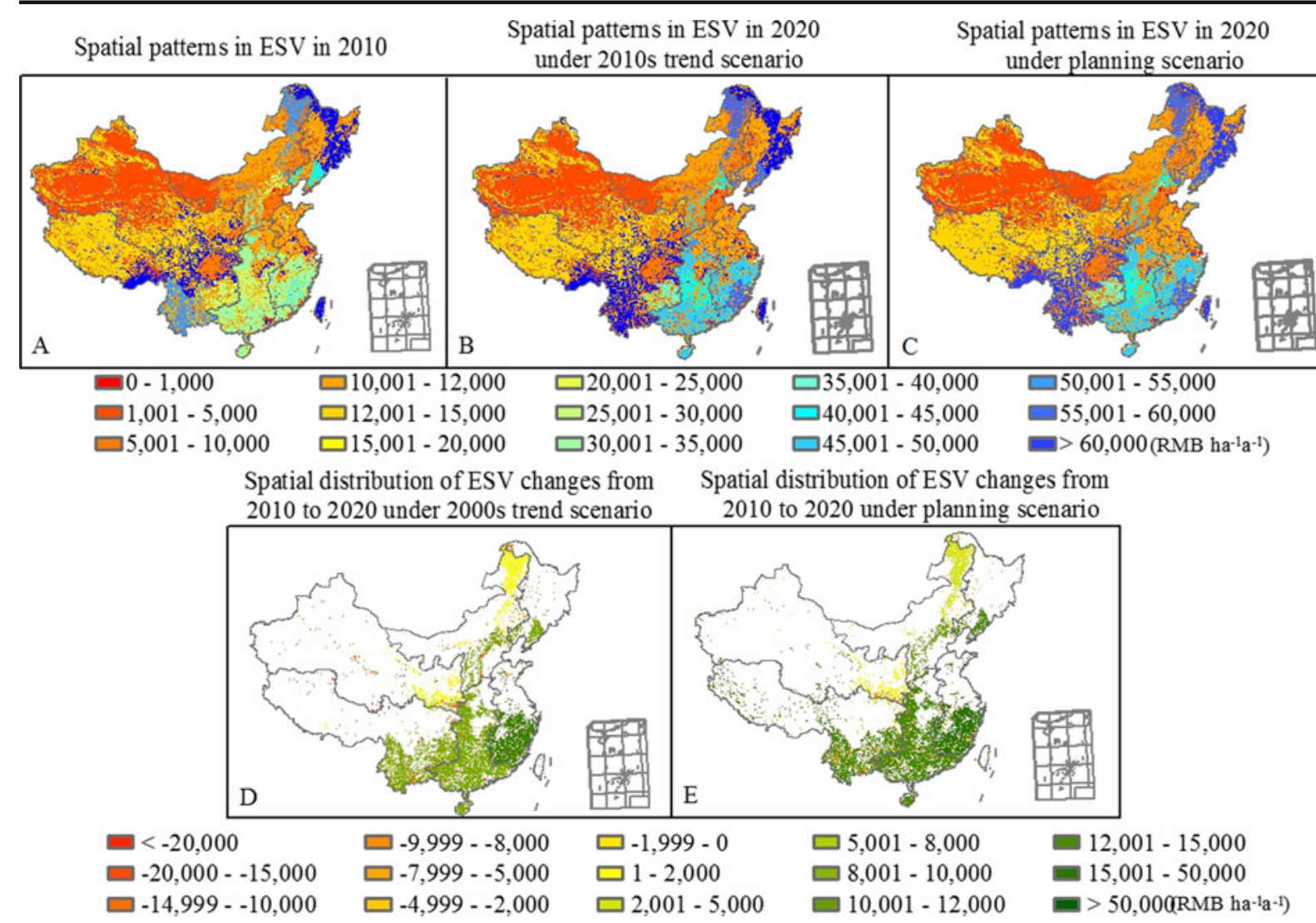

Fig. 3 Spatial pattern of ESVs in China in 2010 (a), 2020 under the 2000s scenario (b), 2020 under the planning scenario (c), and changes between 2010 and 2020 under the 2000s trend scenario (d) and the planning scenario (e)

national maps of ESV in 2010 and in 2020 under the 2000s trend scenario and the planning scenario. The result is useful for supporting decision-making during sustainable development at the regional level. To the best of our knowledge, there is still no other study that takes biomass into consideration when estimating ESVs in China.

In this study, two land use scenarios were developed, the 2000s trend scenario and the planning scenario. However, the results of these two scenarios are not in opposite directions, and the total ESV values in both scenarios increased during 2010-2020. In late twentieth century, national ecological restoration programs started to be carried out, such as the ecological returning to forest project, the natural forest protection project, and the three north shelter forest projection. As a result, the woodland showed an increase trend between 2000 and 2010. Therefore, in the 2000s trend, the woodland would also increase, but the increased value is relatively smaller than the planning scenario.
Spatial patterns of land use in 2020 under the 2000s trend scenario and the planning scenario were simulated first. Relatively high-to-moderate ROC values were found for forest (0.817) and grassland (0.810). These differences in good-of-fit occurred because built-up land lies in locations with specific characteristics (e.g., high population and high GDP, close to roads, moderate slope), similar to the cropland that forms in area with certain drainage and clay texture conditions. Whereas grassland and forest could be found in altitude zones and represent a wide range of different activities; hence, lower ROC values were received.

The method to adjust the ecosystem service values in this study was based on a hypothesis that the ESV has a good positive correlation with biomass. However, this hypothesis is not always reasonable for all land use types. The species composition, distribution, and diversity, and the human landscape could also have some effects on the ESV except for the biomass. There are considerable uncertainties 

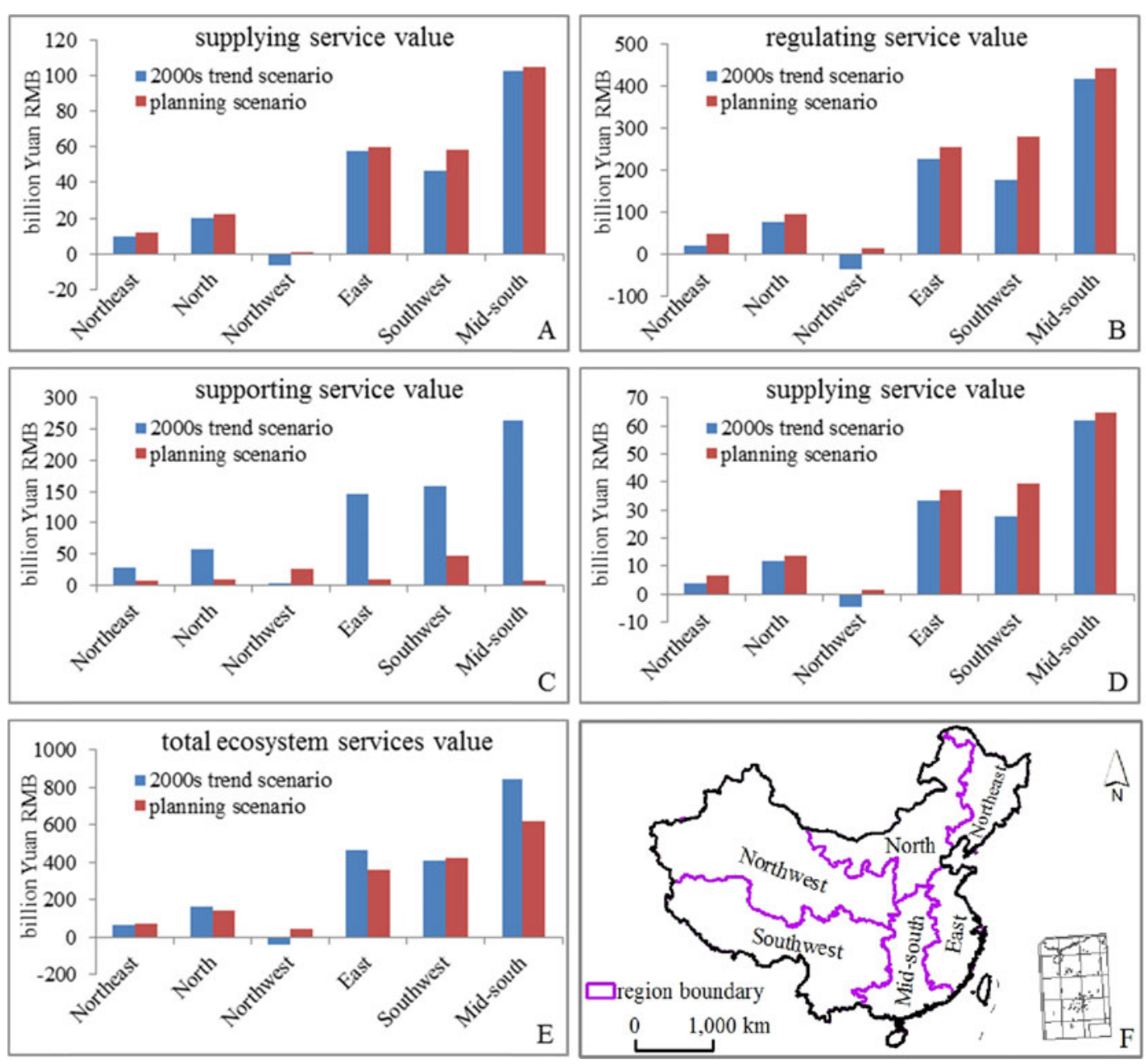

Fig. 4 Projected changes under the two scenarios (the blue bar for the BAU scenario and the red bar for the planned scenario) relative to 2010 for a supplying services, b regulating services, c

supporting services, $\mathbf{d}$ cultural services, $\mathbf{e}$ total ecosystem services of different regions, and (f) the region boundary. The bars in a-e display the difference between the two scenarios and 2010

associated with the modeling and calculations of ESVs. First, the validation of the land use simulations can be possible for historical land use changes only. There is no guarantee that it will work in the future, since it only provides an indication of the validity in the downscaling procedure and the allocation algorithm of the model. Evidences from other studies indicate that the relationship can be stable over one or two decades despite land use changes (Schulp et al. 2008). Second, the value transfer method used in this study is widely criticized. One of the errors in ecosystem service mapping based on value transfer is associated with the failure to include spatial variability in biophysical measurements of ecosystem services, and the ecosystem service for a particular land cover type is constant across the entire area being mapped

(Eigenbrod et al. 2010). Despite the demerit of value transfer method, currently it is still a useful way to estimate the value of ecosystem services. At the national scale, the collection of primary data is constrained, and the value transfer method can be used to estimate the ecosystem service values with lower expenses than primary survey. The correction and adjustment applying the biomass data in this study could reduce the uncertainties and improve practical accuracy in mapping the ESVs. Third, in line with previous studies (Xie et al. 2008; Wang et al. 2014), the ecosystem service values of built-up land were assumed to be zero since the ESV coefficients of built-up land are unavailable. However, the built-up land may have negative regulating and supporting service values (Wu et al. 2015), and the urban green 
is able to provide ecosystem services (Long et al. 2014). Fourth, market and biophysical forces such as societal preference shift, the development of new technologies, and natural disasters $\mathrm{t}$ as well as the ESV coefficient variation cannot be anticipated and taken into consideration in our study. Last but not the least, despite these modeling caveats, the results provide an empirically estimation of the effect of land use change on ecosystem services. Since the primary goal of this study is to explore the effects of land use change rather than to predict future land use, unanticipated events and the defects in method will influence future land use under both scenarios. Therefore, the predictions of the difference between scenarios are less uncertain than the prediction of future condition itself.

\section{Conclusion}

In this study, we developed a spatially explicit method to examine the effects of land use change on ecosystem service values by projecting future land use change under the 2000s trend scenario and the planning scenario, and integrating land use change dynamic model and ecosystem service valuation methods. We found that in 2010, the ESV could be estimated at RMB 18,766.94 billion in China, and approximately $60 \%$ of the ESV is contributed by woodland. Focus should be in the value of forest ecosystems. The ESV values in 2020 increased 1798 billion Yuan RMB a ${ }^{-1}$ under the 2000s trend scenario and 2215 billion Yuan RMB a ${ }^{-1}$ under the planning scenario compared with 2010 . We found that the adjusted ESV map by biomass presented a logical national geographic distribution. The high ESVs occurred primarily in northeastern and southern China, while the places with ESV value lower than 5000 RMB ha ${ }^{-1} \mathrm{a}^{-1}$ were located in the northwestern China. The increase of ESV mainly occurred in southern China where the forest coverage was high.

We hope that the results of this study can serve as an alternative tool for assessing sustainability and green GDP. Theoretically, the ESV maps with spatial information can provide more information and support than simply a national accounting spreadsheet. Practically, this easily used method for simulating ESV spatially can help avoid or mitigate negative impact on ecosystems, and the study can be a reference for national institutions and programs, such as the land use planning department and national ecological projects.
Acknowledgments This work is supported by the National Natural Science Fund of China (41501428), National Fundamental R\&D Program of the Ministry of Science and Technology of the People's Republic of China (2013FY111600-4), the Key Laboratory of the Coastal Zone Exploitation and Protection, Ministry of Land and Resource (2015CZEPK02), and Science and Technology Planning Project of Qufu Normal University (xkj201318).

\section{References}

Andrew, M. E., Wulder, M. A., \& Nelson, T. A. (2014). Potential contributions of remote sensing to ecosystem service assessments. Progress in Physical Geography, 38, 328-353.

Baral, H., Keenan, R. J., Sharma, S. K., Stork, N. E., \& Kasel, S. (2014). Economic evaluation of ecosystem goods and services under different landscape management scenarios. Land Use Policy, 39, 54-64.

Bateman, I. J., et al. (2013). Bringing ecosystem services into economic decision-making: land use in the United Kingdom. Science, 341, 45-50.

Chi, H., Sun, G., Huang, J., Guo, Z., Ni, W., \& Fu, A. (2015). National forest aboveground biomass mapping from ICESat/ GLAS data and MODIS imagery in China. Remote Sensing, 7, 5534-5564.

Contanza, R., et al. (1997). The value of the world's ecosystem services and natural capitals. Nature, 387, 253-260.

Costanza, R., et al. (2014). Changes in the global value of ecosystem services. Global Environmental Change, 26, 152-158.

Eigenbrod, F., et al. (2010). The impact of proxy-based methods on mapping the distribution of ecosystem services. Journal of Applied Ecology, 47, 377-385.

Fan, Z. M., Zhang, X., Li, J., Yue, T. X., Liu, J. Y., Xiang, B., \& Kuang, W. (2013). Land-cover changes of national nature reserves in China. Journal of Geographical Sciences, 23, 258-270.

Fang, J. Y., Liu, G. H., \& Xu, S. L. (1996). Carbon pools in terrestrial ecosystems in China. Beijing: Chinese Science and Technology Publisher.

Fang, J. Y., Wang, G. G., Liu, G. H., \& Xu, S. L. (1998). Forest biomass of China: an estimate based on the biomass-volume relationship. Ecological Applications, 8, 1084-1091.

Foley, J. A., et al. (2005). Global consequences of land use. Science, 309, 570-574.

Fürst, C., Frank, S., Witt, A., Koschke, L., \& Makeschin, F. (2013). Assessment of the effects of forest land use strategies on the provision of ecosystem services at regional scale. Journal of Environmental Management, 127, S96-S116.

Jiang, W., Chen, Z., Lei, X., Jia, K., \& Wu, Y. (2015). Simulating urban land use change by incorporating an autologistic regression model into a CLUE-S model. Journal of Geographical Sciences, 25, 836-850.

Lawler, J. J., et al. (2014). Projected land-use change impacts on ecosystem services in the United States. Proceedings of the National Academy of Sciences, 111, 7492-7497.

Li, W., \& Wu, C. (2013). A spatially explicit method to examine the impact of urbanisation on natural ecosystem service values. Journal of Spatial Science, 58, 275-289. 
Liu, J. Y., Zhuang, D. F., Luo, D., \& Xiao, X. (2003). Land-cover classification of China: integrated analysis of AVHRR imagery and geophysical data. International Journal of Remote Sensing, 24, 2485-2500.

Long, H., Liu, Y., Hou, X., Li, T., \& Li, Y. (2014). Effects of land use transitions due to rapid urbanization on ecosystem services: implications for urban planning in the new developing area of China. Habitat International, 44, 536-544.

Martínez-Harms, M. J., \& Balvanera, P. (2012). Methods for mapping ecosystem service supply: a review. International Journal of Biodiversity Science, Ecosystem Services \& Management, 8, 17-25.

McConnell, W.J., Sweeney, S.P., Mulley, B. (2004). Physical and social access to land: spatio-temporal patterns of agricultural expansion in Madagascar. Agriculture, Ecosystems and Environment.

Nabuurs, G. J., Pussinen, A., van Brusselen, J., \& Schelhaas, M. J. (2007). Future harvesting pressure on European forests. European Journal of Forest Research, 126, 391-400.

Newbold, T., et al. (2015). Global effects of land use on local terrestrial biodiversity. Nature, 520, 45-50.

People's Daily online. (2008). National general land use planning outline. Available online at http://politics.people.com.cn/GB/ 1026/8222549.html (in Chinese).

Piao, S. L., Fang, J. Y., Zhou, L. M., Tan, K., \& Tao, S. (2007). Changes in biomass carbon stocks in China's grasslands between 1982 and 1999. Global Biogeochemical Cycles, 21, GB2002.

Piao, S. L., Fang, J. Y., Ciais, P., Peylin, P., Huang, Y., Sitch, S., \& Wang, T. (2009). The carbon balance of terrestrial ecosystems in China. Nature, 458, 1009-1014.

Pontius, R. G., Jr., \& Millones, M. (2011). Death to Kappa: birth of quantity disagreement and allocation disagreement for accuracy assessment. International Journal of Remote Sensing, $32,4407-4429$.

Schulp, C. J. E., Nabuurs, G. J., \& Verburg, P. H. (2008). Future carbon sequestration in Europe - effects of land use change. Agriculture, Ecosystems \& Environment, 127, 251-264.

Song, W., Deng, X., Yuan, Y., Wang, Z., Li, Z. (2015). Impacts of land-use change on valued ecosystem service in rapidly urbanized North China Plain. Ecological Modelling.

Su, S., Xiao, R., Jiang, Z., \& Zhang, Y. (2012). Characterizing landscape pattern and ecosystem service value changes for urbanization impacts at an eco-regional scale. Applied Geography, 34, 295-305.

Sun, X., Yue, T., Wang, M., Fan, Z., \& Liu, F. (2015). Effects of land use planning on aboveground vegetation biomass in China. Environmental Earth Sciences, 73, 6553-6564.

Swetnam, R. D., et al. (2011). Mapping socio-economic scenarios of land cover change: a GIS method to enable ecosystem service modelling. Journal of Environmental Management, 92, 563-574.

Syswerda, S. P., \& Robertson, G. P. (2014). Ecosystem services along a management gradient in Michigan (USA) cropping systems. Agriculture, Ecosystems and Environment, 189, 2835 .

TEEB (2010) The economics of ecosystems and biodiversity: ecological and economic foundations. London and Washington: Earthscan.

Verburg, P. H., \& Overmars, K. P. (2009). Combining top-down and bottom-up dynamics in land use modeling: exploring the future of abandoned farmlands in Europe with the DynaCLUE model. Landscape Ecology, 24, 1167-1181.

Wang, W., Guo, H., Chuai, X., Dai, C., Lai, L., \& Zhang, M. (2014). The impact of land use change on the temporospatial variations of ecosystems services value in China and an optimized land use solution. Environmental Science \& Policy, 44, 62-72.

Wu, M., Ren, X., Che, Y., Yang, K. (2015). A coupled SD and CLUE-S model for exploring the impact of land use change on ecosystem service value: a case study in Baoshan District, Shanghai, China. Environmental Management 1-18.

Xie, G. D., Zhen, L., Lu, C., Xiao, Y., \& Chen, C. (2008). Expert knowledge based valuation method of ecosystem services in China. Journal of Natural Resource, 23, 911-919 (in Chinese).

Yue, T. X., et al. (2005a). Surface modelling of human population distribution in China. Ecological Modelling, 181, 461-478. doi:10.1016/j.ecolmodel.2004.06.042.

Yue, T. X., Wang, Y. A., Liu, J. Y., Chen, S. P., Tian, Y. Z., \& Su, B. P. (2005b). SMPD scenarios of spatial distribution of human population in China. Population and Environment, 26, 207-228.

Zheng, H. W., Shen, G. Q., Wang, H., \& Hong, J. (2015). Simulating land use change in urban renewal areas: a case study in Hong Kong. Habitat International, 46, 23-34. 